\title{
The Relative Contribution of Spiritual Intelligence in the Adherence to Research Ethical Standards
}

\author{
Boshra I Arnout ${ }^{1}$, Oleg Y Latyshev ${ }^{2}$ and Ahed J Alkhatib*3,4 \\ ${ }^{1}$ Department of psychology, Faculty of education, King Khalid and Zagazig University International Mariinskaya Academy, \\ Chief Scientific Secretary, Academician secretary of department of Psychology \\ ${ }^{2}$ Academician of the, Russian Academy of Natural History, President of International Mariinskaya Academy
}

${ }^{3}$ Department of Legal Medicine, Toxicology of Forensic Science and Toxicology, School of Medicine, Jordan University of Science and Technology, Jordan.

${ }^{4}$ International Mariinskaya Academy, department of medicine and critical care, department of philosophy, Academician secretary of department of Sociology

*Corresponding author: Ahed J Alkhatib, Department of Legal Medicine, Toxicology of Forensic Science and Toxicology, School of Medicine, Jordan University of Science and Technology, Jordan

\section{ARTICLE INFO}

Received: 慧 June 08, 2019

Published: 蔧 June 14, 2019

Citation: Boshra I Arnout, Oleg Y Latyshev, Ahed J Alkhatib. The Relative Contribution of Spiritual Intelligence in the Adherence to Research Ethical Standards. Biomed J Sci \& Tech Res 18(5)2019. BJSTR. MS.ID.003216.

Keywords: Spiritual Intelligence; Adherence to Research Ethical Standards; Scientific Degree

\begin{abstract}
This study aimed to determine the level of spiritual intelligence and adherence to the research ethical standards among academic researchers, and to reveal the relative contribution of spiritual intelligence in predicting adherence to the research ethical standards, as well as to identify the differences in both spiritual intelligence and adherence to the research ethical standards due to (gender, scientific degree) variables. The researchers selected a random sample of (203) of the academic researchers. Their ages ranged between (32-50) years. The researchers applied the scale of spiritual intelligence and the scale of adherence to the research ethical standards. The results showed that there was a low level of spiritual intelligence, but it found an average level of adherence to the research ethical standards. Also, there were statistically significant differences $(0.05)$ among the mean scores in spiritual presence and spiritual intelligence due to gender in favor of females, but not found a statistically significant differences in spiritual mindfulness, spiritual abilities and adherence to the research ethical standards. The results also found statistically significant differences in spiritual mindfulness, spiritual abilities and adherence to the research ethical standards due to scientific degree in favor of professor's researches. The results of the simple regression analysis also indicated that spiritual intelligence is a significant and powerful indicator of adherence to the research ethical standards.
\end{abstract}

\section{Introduction and Literature Review}

In the present, the studies of psychology have moved steadily towards positive psychology in their study of positive experiences and characteristics in human personality such as happiness, optimism, self-organization, personal competence, hope, forgiveness, emotional intelligence, and spiritual intelligence. This age requires a human being with the physical, psychological, educational and spiritual qualities and abilities that enable them to live in happiness and peace and enable them to overcome the negative stress that whispers inside, the orientation towards ourselves, life, and others. The human mind is designed by the almighty creator to avoid hardship, pain, tension and stress, and to strive for a sense of comfort and tranquility. This is why we are motivated to improve our physical, emotional, psychological and spiritual abilities and commit ourselves to the best of our potential and energy, especially in this area of successive changes in all aspects of life and in different branches of science and spiritual intelligence vital to all persons particularly for academic researchers. Scientific research is the cornerstone of the university's accreditation as a productive institution and one of the quality indicators. There is no doubt that the importance of scientific research in our lives to achieve the welfare of society and the health of individuals. Scientific research is an investigation of a survey, empirical or descriptive nature led by a question, and hypothesis. 
Scientific research includes any intellectual or creative work published, presented, displayed or performed in written, spoken, electronic, visual or other media. Scientific research is of great importance in achieving progress and excellence at all levels through its foundations, methods, tools and methodology that help to solve problems in any field of life. Thus, any society that seeks progress and wishes to achieve intellectual and social renaissance must be interested in scientific research as a source of knowledge Ibrahim [1]. University research is subject to policies and practices that ensure the protection of research participants and researchers. These policies and practices cover research involving humans, the use of animals, controlled goods, hazardous materials, etc., in order to achieve the integrity of scientific research, which is the reliability of research resulting from the safety of methods, the genuineness and accuracy of its results. Thus, the concept of scientific research emphasizes the need to use scientific methodology. But the question here is: Is scientific methodology alone enough to raise the value of research and its importance? There is no doubt that scientific methodology alone is not enough to judge the value of research. In addition, the researcher must be committed to ethics in the various steps of the research, so that its results are valuable and useful to society and accepted by individuals and various institutions concerned with scientific research.

\section{Ethics and Integrity of Scientific Research}

The integrity of scientific researches refers to honest commitment to relevant ethical, disciplinary and financial standards in the promotion, design, conduct, evaluation and participation of research. It includes several principles:

a. Truthfulness,

b. Reliability,

c. Use of strong research methodologies,

d. Neutrality and independence,

e. Open communication,

f. Duty of care of participants,

g. Justice,

h. High standards of guidance and scientific supervision,

i. Awareness of responsibility towards society.

The violation of these nine principles of the integrity is a scientific and professional misconduct of researchers University of Cambridge [2]. Intellectual freedom and honesty are essential to the participation and development of scientific knowledge. In order to show the commitment of researchers to these fundamental values, all members of the university community must be demonstrating the integrity in their education, learning, research and personal behavior. Individuals are responsible for the intellectual and moral quality of their scientific works, so they must make sure that their researchers meet university standards and are responsible for knowing what constitutes appropriate academic conduct University of South Africa [3]. The integrity of scientific research and the ethical behavior of academic researchers have been widely discussed as important issues in the scientific community. These factors are understood to refer to the use of honest and verifiable methods of proposing, implementing and evaluating scientific research. Integrity of research involves adherence to accepted rules, regulations, guidelines, rules and standards. Values in scientific research include honesty, accuracy, effectiveness and objectivity. Researchers must communicate information with intellectual honesty, and this involves sincerity and lack of deception. Accuracy in statistical analysis and evaluation of the scientific values of the research community are included correctly. Effectiveness includes the ability to achieve results without wasting or misusing resources, efforts or funds. Objectivity refers to avoiding scientific prejudice that may interfere with research, such as the intervention of a person's beliefs or values $[4,5]$.

The integrity of scientific research is a prerequisite for those who work in all fields. Integrity is absent when the researcher is involved in the distortion or falsification of data or scientific plagiarism and thefts. Awad [6] said that academic robbery is a serious phenomenon that is experienced by educational institutions in various countries of the world. It seems that the internet itself has contributed to the spread of this phenomenon, where they appear on many websites, which puts before them a huge amount of scientific materials directed to their needs related to writing researchers. Three theories have prevailed in the history of ethical principles. The theory of ethics was introduced in the 18th century by the philosopher Kant; this theory deals with ethics or standards and principles that govern behavior in relation to the absolute rules that have been developed within society. For example, it may be unethical for a researcher to distort the results of a research or provide an intervention or product that has no evidence-based results. The second theory is the theory of sequential consequences that includes the path of behavior used to solve a problem. For example, if the path chosen to resolve the issue is unethical, the search may result in untrue negative results. In this case, the falsification of the results may include waste of money, loss of reputation or adverse effects. In the twentieth century pragmatic theory developed. This theory emphasizes that ethics evolve over time and are closely related to the development of scientific knowledge. For example, research that emerged in mid1900 revolves around evidence-based methods of assessment and intervention. By attending conferences and reading research in evidence-based journals, students and professionals can follow the progress in the ever-changing landscape of scientific research [7].

The main ethical duties of researchers derive from religion, social norms and universal scientific ethical values, and there is an inherent commitment to researchers to respect the presuppositions of any science, as well as to reveal the new and true results. Ethics is the code of conduct that distinguishes acceptable and unaccept- 
able scientific behavior, and social traditions play an important role in establishing the credibility of scientific knowledge. At the international level, several universities require research in accordance with high standards of honesty, rigor, transparency, open communication, respect for all participants and subjects studied, in that most professions are governed by ethics. Moral behavior consists of behaviors and decisions that benefit participants in scientific research. Ethical behaviors also play a role in diagnosis, assessment and treatment. Within ethical thinking, the decision-making process involves considering alternative paths of action, as well as considering possible responses or outcomes for each track. Negative results may emerge if the chosen course of action is contrary to ethical principles. Despite universal recognition of integrity and ethical conduct, there have been instances of immoral behavior [8].

Guraya, London et al. [9] who reviewed 461 published studies in a foreign databases (ISI web of knowledge, Science direct, Google Scholar, the Cochrane database), and reviewed its commitment to ethical standards of scientific research, found that (21) studies were committed to the ethics of scientific research, and that ethics is the fundamental dimension in theoretical and applied research. There were at least 30 allegations of violations of scientific research ethics between 2012 and 2015. Data obtained under the freedom of information regulations identified hundreds of allegations of violations of ethical standards of scientific research in 23 universities over a similar period. These examples of violations of the ethics of scientific research pointed to growing concern around the world regarding the integrity of research and ethical behavior. Therefore, it is important that universities and institutions teach students and researchers the ethics of scientific research, confirming the ethics of the research ethics committee of each university before publishing them, and review research efforts to determine ethical behavior [10]. In the process of research and supervision irresponsible and unfair in the evaluation of research and scientific messages and falsification of the results of research and fabrication and the increasing literary plagiarism among researchers, make the fate of scientific research-especially in Arab countries unknown.

Research should be based on the appropriate scientific procedures for the research questions. Questions should provide relevant knowledge, avoid unnecessary copying, and obtain technical or theoretical support leading to the ability to repeat studies. The researcher should also report contributions and follow the guidelines. And that the published research should be carefully planned and considered in writing the origins of scientific writing, with systematic and ethical accuracy. Scientific research has ethical standards which provide guidelines that research must adhere to ethical principles to protect the dignity, rights and welfare of its participants. To achieve this aim, peer-reviewed research should be reviewed by the University Ethics Committee to ensure that appropriate ethical standards are met in research and funding. As a result of the realization of the importance of commitment to them, many Arab universities have developed a guide to the ethics of scientific research that direct researchers in their scientific activities from learning, research, teaching, supervision and other scientific activities.

Scientific research is suffering from overcrowding in the Arab libraries with a declining scientific production. This decline is due to the lack of originality, where there is no independence of realistic thought, the spread of scientific thefts, and the violation of the curriculum and its origins [11]. There are three objectives of the adherence to ethics of scientific research, the first and most important objective: is to protect human participants. The second objective is to ensure that research is carried out in a way that serves the interests of individuals, groups or society. Finally, the third objective is to study specific research activities and projects in order to ensure ethical integrity, and to consider issues such as risk management, confidentiality protection and informed consent process [9]. To foster a high-level scientific community of researchers, it is important to encourage continuing education and international cooperation to share and develop knowledge. Creativity, ethics and integrity in research practices are fundamental to universities and scientific research institutions in the world, a recurrent theme in the major policy agendas of scientific research centers [12].

The manipulation of research results and misrepresenting the search community's options and preferences are not limited to novice students and researchers but include senior researchers. Examples include the confessions of Eric Poelman, a scholar of aging at the University of Vermont, He admitted to fabricating the data in fifteen applications for federal grants and ten published papers [13]. One of the reasons why it is important to adhere to ethical standards is that the ethical rules promote the achievement of scientific research objectives such as knowledge, truth, and avoid mistakes. For example, being cautious about changing, distorting, and fabricating data enhances the presentation of facts as they do and reduces errors. Second, since research often involves a great deal of cooperation and coordination among many different people in different disciplines and institutions, adherence to ethical standards of scientific research strengthens the core values of cooperative action, such as trust, accountability, mutual respect and justice. For example, authoritative guidelines, copyright and patent policies, data sharing policies and confidentiality rules in peer review, to protect intellectual property interests while promoting cooperation. For the third reason, ethical standards help ensure that researchers are accountable to society. Fourthly, ethical standards in research help build public support for research. Research is likely to be funded and financially supported if the quality and moral integrity of the research is trusted. Finally, many research ethics promote a multitude of other important ethical and social values, such as social responsibility, human rights, animal welfare, law compliance, health and public safety. Moral failures in scientific research can cause significant harm to society and its members [14].

This is confirmed by an analytical descriptive study by Fawaz [15] titled "Ethics of Scientific Research". The results revealed that 
there are many cases that indicate the existence of the phenomenon of distance from the ethics of scientific research, which necessitates finding means to control and strengthen this ethics in the researcher. The absence of the ethics of scientific research is not an individual case, but it is up to the level of phenomenon, not limited to a particular society, even the West is witnessing many cases of distancing from the ethics of scientific research when written, despite the differences between communities on the prevalence of this phenomenon. This study recommended the necessity of conducting statistical studies on the degree to which the Arab researcher adheres to the ethics of scientific research, because science and ethics are two sides of a single coin, scientific research is not compatible without them. If we want valuable scientific research that contributes to the service of humanity, it is necessary to pay attention to the moral aspect and evaluate it. In the same way, the study of Arnout [16] found that the level of adherence to research ethics among researchers in educational science was low.

\section{Spiritual Intelligence}

James began to pay attention to the spiritual aspect and its role in solving life problems and giving value and meaning to life. He published his book "Variety of spiritual intelligence". He assumed that the spiritual aspect makes human life meaningful, makes its use logical behavior and is committed to life, He also makes his relationship to others based on faith, and thus the individual has a positive attitude towards others and towards the whole of humanity [17]. Individual possesses mental and emotional ability, and besides these abilities there is a third capacity of great importance given by his humanity is spiritual capacity, and this ability is measurable, such as mental and emotional ability. In the review of the theoretical heritage written in spiritual intelligence, there are two perspectives regarding the nature of spiritual intelligence and its components in the individual. The first is that it is a human ability that generates a person and can be developed. Among the scientists belonging to this perspective are [18-23] and the second view that spiritual intelligence is a skill and one of those who followed this attitude is Wigglesworth [24]. Based on these two perspectives, several scales of spiritual intelligence were proposed, whether as ability or skill.

\section{The importance of spiritual intelligence:}

Spiritual intelligence is important to individuals; Costello [25] emphasized the importance of spiritual intelligence for the following reasons:

a. Provides individual with a reason for existence.

b. Helps individual to know his conscience and how to preserve it considering the latest developments in life.

c. Helps individual how to draw his way of life.

d. Creating the meaning of moral authority.

e. It gives individual the ability to see things more clearly.

f. Develop the true meaning of values. g. Allows a person to dream of real success, which gives him the desire to struggle for it.

h. Supports the things person believes in.

i. Directs person to take the necessary measures to achieve his aims.

Therefore, the importance of spiritual intelligence is clearly for academic researchers, it helps them to achieve the aims of their studies, and to develop the meaning of academic life, scientific activities and gives them the desire to struggle although the stressors they confront in their academic and family life. Vama Mar [26] pointed out that spiritual intelligence frees an individual from destitution in his personal relationships when he realizes that he has what others have (love, happiness, peace) and then acts freely and interacts with them without any personal interests. This deep foundation for any open, healthy and harmonious relationship based on spiritual values is based on respect and trust. Spiritual intelligence in the family context allows individuals to find more mature means of emotional independence and helps them contain and accept others regardless of their behavior or emotional state.

\section{The component of spiritual intelligence}

King [23] noted that spiritual intelligence is capable, and identified the components of spiritual intelligence from the following four capacities:

a. Critical existential thinking: This mental capacity means the ability to produce and create a meaning based on a deep understanding of questions about existence and awareness, and the ability to use different levels of feeling to solve problems.

b. The production of personal meaning or production includes the ability of the person to integrate his physical and mental experiences with personal meaning, which leads to increased satisfaction.

c. Transcendental Awareness is related to the ability to understand one's relationship to all beings by being, and includes the ability to coordinate between different scenes, and the ability to use them also for a deep understanding of interaction and mutual relations with oneself and others.

d. Conscious State Expansion describes this component as the viability of concentration, the ability to indulge when directing goals, analytical thinking, the ability to tolerate and tolerate, accept unusual or contradictory experiences, it is associated with pure cognition, insight, increased empathy, better concentration, and greater intuitive sense.

As well, Arnout [27] proposed three dimensions consisting of spiritual intelligence:

\section{a) First Dimension: Spiritual Mindfulness}

It refers to the individual's awareness of realism and strong presence in different situations, understanding the ideas and 
behavior of others, as well as the recognition of the links between different things in the surrounding universe, making it easier to adapt to the changes of life and developments.

\section{b) Second dimension: Spiritual Abilities}

The ability to be open to others and to establish good social relations as well as the ability to re-frame the situation, allowing him to be in harmony with himself and others, and the formation of a positive trend towards Himself and the world around him.

\section{c) Third Dimension: Spiritual Presence}

It means that the individual enjoys a good appearance and a balanced physical language that indicates self-confidence, personal attractiveness and lightness, and the love, acceptance and tolerance of others, as well as cooperation and partnership with them, allowing him to form good relations and resolve differences.

There has been a growing interest in studying the spiritual intelligence of different groups, students, workers, administrators, ordinary people and people with special needs. However, research has not been directed to study the spiritual intelligence of researchers, despite the importance of this variable for this category that leads the development of societies. Ahmad (2004) pointed out that Spiritual intelligence is the basic method of knowledge. We use it to visualize unrealized possibilities or to transcend stereotypes of life. We also use it to understand pain, to answer philosophical questions about life, and to create meaning in real or existential terms. Spiritual intelligence is therefore a center and source of guidance for other human scents, a compass destined for life. Therefore, we must pay attention to our spiritual intelligence and develop it. The interest of those who will die tomorrow, and the interest in physical intelligence, is the attention of those who suffered a heart attack yesterday and have been saved by God.

The interest in social intelligence is the concern of those who know that others will care about everything he says to them. Of information that will expire two years later. If we notice the seven things that according to Gandhi will destroy us: wealth without work, unscrupulous pleasure, knowledge without character, trade without ethics, science without humanity, worship without sacrifice, policy without principles. It is the ego at the expense of everyone and without regard to anyone, we will without doubt realize the importance of spiritual intelligence in our world today (Covey, 2000). Spiritual intelligence, in the words of Vaughan [28], is more than an individual mentality. It connects the person with the God and the self in spirit. Spiritual intelligence transcends traditional psychological growth. It opens the heart, illuminates the mind and inspires the spirit, enables man to distinguish between reality and fantasy, and to discover the hidden springs of love and joy under pressure and daily life problems, and to see things as they are away from unconscious distortion. Express it through any culture as love, wisdom and service. Joseph [29] adds that spiritual intelligence can be seen in the light of a sense of purpose, trust, empathy, harmony with nature, and a sense of well-being, whether alone or in a group.
Several studies have been conducted on spiritual intelligence. Including the study of Amram and Drier [22] on different age groups from age 18 to 65 and above, the results of the study found that spiritual intelligence increases with age. Arnout [30] conducted a study to detect the relationship of spiritual intelligence to the five major personality factors of university students and staff, the results indicated that there are differences in spirit intelligence due to age, older age was higher in spiritual intelligence, there were also differences in spiritual intelligence between the males and females, and the differences were in favor of females. And Arnout [31] conducted another study to identify the relationship between spiritual intelligence and quality of life on a sample of employees of some government institutions, the results indicated differences in spiritual intelligence between the males and females and differences were in favor of females. Amrai et al. [32] conducted a study to identify the relationship between spiritual intelligence and personality traits on a sample of university students, the results found a relationship between spiritual intelligence and personality traits.

Beshlideh et al. [33] conducted a study targeting university students and found a relationship between spiritual intelligence and personality traits. Abadi [34] conduct a comparative study between fasting and non-fasting in spiritual intelligence and happiness, and results found that spiritual intelligence and happiness are high among fasting, the results of the study found that there are no statistically significant differences between males and females in spiritual intelligence, and the Arnout [27] study on a sample of high school students, university students and employees, results found that there are differences in spiritual intelligence between males and females in favor of females.

From these previous studies, researchers noted that the previous studies interested in spiritual intelligence among students and employees in different jobs, while there is no any interest in the study of spiritual intelligence among academic researchers. Also, there is no any interest in studying the relationship between spiritual intelligence and the researchers adherence to the research standards although the importance of spiritual intelligence in shaping the personality of individuals as has shown by the results of the previous studies such as [32,34]. Therefore, the present study is a response for this shortcoming and as an attempt to identify the predictability of spiritual intelligence to adhere to the research ethical standards. The previous studies were conducted a few descriptive analytical studies on ethics scientific research and did not dealt with the researchers' spiritual intelligence and adherence to the ethics of scientific research, which is interested in the current study.

\section{Objectives of the study}

This study sought to examine whether spiritual intelligence can predict the scores of adherence to the research ethical standards, and to reveal the level of spiritual intelligence and adherence to the research ethical standards among researchers, and to detect 
the differences in both spiritual intelligence and adherence to the research ethical standards due to gender and scientific degree, as well as revealed the predictability of spiritual intelligence in the adherence to research ethical standards, in order to improve researches, the academic programs and for obtain institutional accreditation of universities.

\section{Methods and subjects}

\section{Research Design}

A cross sectional descriptive design was used to examine the predictability of spiritual intelligence to researchers' adherence to the research ethical standards.

\section{Study Participants}

A random sample was selected from the academic researchers in natural sciences (33), special education (13), psychology (38), social science (37), curriculum and teaching methods (34), administration and human resources (21), and applied language (17). The final sample of the study was (203) researchers, 111 of them were males and 92 females, were between the ages of ( 32 to 50 ) year. Of these, 106 were assistant professors, 43 were associate professors, while (54) of them were professors.

\section{Study Instruments}

Spiritual Intelligence: Spiritual intelligence was assessed using the scale of spiritual intelligence [16]. The 27-items scale SIS rates individual response on 4-point Likert scale 1= "rarely" and 4= "often" with higher scores indicates more spiritual intelligence. It consists of 3 distinct dimensions: spiritual mindfulness, spiritual abilities, and spiritual presence. The scale has been reduced to 9 items per dimensions. The validity and stability of this scale was verified. The validity and reliability were calculated. An internal consistency coefficient index ranged between 0.850 to 0.896 , and alpha was (0.950).

Adherence to Research Ethical Standards: Adherence to research ethical standards was measured with the scale of adherence to research ethical standards. This scale consists of 60 items. Respondents rated themselves on each item according to a 5point Likert scale from (always $=5$, often $=4$, sometimes $=3$, rarely $=2$, never $=1$ ). Higher scores imply high adherence to the research ethics. It consists of 6 distinct dimensions: Ethical standards for search procedures, intellectual property, social responsibility, scientific supervision and reviewing studies, and for the rights of other researchers. The original scale was developed by Arnout [16] had 60 items contained within each of the 6 dimensions, this has been reduced to 10 items per dimension. The validity and stability of this scale was verified.

\section{Study Procedure}

Ethical approval was obtained from research committee of the participants. The researchers sent an online link of the study tools to the study participants in their accounts in Research gate, Facebook and e-mail. They answered the question about their desire to participate in this study. The researchers emphasized that the study is an academic exercise and the data would be used only for the purpose of the study. Upon completing the measures, participants were debriefed and thanked for their participation.

\section{Data analysis}

Preliminary analyses included descriptive statistics, t-test, and ANOVA for test differences after verified the normality of data in spiritual intelligence and adherence to search ethics (skew $=0.480$, 0.354 and kurtosis $=-0.830-,-0.558-$-) respectively.

\section{Study Results}

Results in Table1 indicated that the total score of spiritual intelligence was low with a mean of (55.473), which is less than the test value of (67.50) and a standard deviation of (16.551). The sub-dimensions of the spiritual intelligence were also low with means of $(18.418,18.438$, and 18.616) which were also less than the test value (22.50) and a standard deviation of (5.779, 5.786, and 6.147). The value of "t- test" for one independent group was statistically significant for the differences between the means and the theoretical means of the sub-dimensions as well as the total score. These results have been tested for significance at the level of 0.05 .

Table 1: Scores of spiritual dimensions (One- sample test).

\begin{tabular}{|c|c|c|c|c|}
\hline Measure & M & Test value & SD & t \\
\hline Spiritual Mindfulness & 18.418 & 22.50 & 5.779 & 10.061 \\
\hline Spiritual Abilities & 18.438 & 22.50 & 5.786 & 10.002 \\
\hline Spiritual Presence & 18.616 & 22.50 & 6.147 & 0.000 \\
\hline Spiritual Intelligence & 55.473 & 67.50 & 16.551 & 0.000 \\
\hline
\end{tabular}

Results in Table 2 indicated that the total score of ethical standards for scientific research was average with a mean of (181.418), which is approximate to the test value of (18.0) and a standard deviation of (5.78). The value of "t- test" for one

Table 2: Score mean of adherence to ethical standards (One- sample test).

\begin{tabular}{|c|c|c|c|c|}
\hline Measure & M & Test value & SD & Sig.(2-tailed) \\
\hline Adherence to ethical standards & 18.418 & 22.50 & 5.779 & 10.061 \\
\hline
\end{tabular}

independent group was statistically significant for the differences between the means and the theoretical means of the total score. These results have been tested for significance at the level of 0.05 . 
Results showed in Table 3 indicated that there are statistically significant differences between the mean scores of males and females in the spiritual presence and spiritual intelligence $(0.047$; 0.032 ) respectively, the differences were in favor of females. While there were no statistically significant differences between the mean scores of males and females in spiritual mindfulness, spiritual abilities and adherence to ethical standards of scientific research scores. These results have been tested for significance at the 0.05 level.

Table 3: Differences in the spiritual intelligence and adhere to ethical standards of scientific research scores between males and females.

\begin{tabular}{|c|c|c|c|c|c|c|}
\hline Measure & Groups & $\mathbf{N}$ & $\mathbf{M}$ & SD & $\mathbf{t}$ & Sig.(2-tailed) \\
\hline \multirow{2}{*}{ Spiritual Mindfulness } & males & 111 & 17.829 & 5.974 & \multirow{2}{*}{1.604} & \multirow{2}{*}{0.110} \\
\hline & females & 92 & 19.130 & 5.484 & & \\
\hline \multirow{2}{*}{ Spiritual Abilities } & males & 111 & 17.540 & 5.829 & \multirow{2}{*}{2.459} & \multirow{2}{*}{0.15} \\
\hline & females & 92 & 19.522 & 5.547 & & \\
\hline \multirow{2}{*}{ Spiritual Presence } & males & 111 & 17.838 & 6.147 & \multirow{2}{*}{1.995} & \multirow{2}{*}{0.047} \\
\hline & females & 92 & 19.554 & 6.046 & & \\
\hline \multirow{2}{*}{ Spiritual intelligence } & males & 111 & 53.207 & 16.814 & \multirow{2}{*}{2.162} & \multirow{2}{*}{0.032} \\
\hline & females & 92 & 58.206 & 15.891 & & \\
\hline \multirow{2}{*}{ Adhere to ethical standards } & males & 111 & 181.639 & 15.235 & \multirow{2}{*}{0.233} & \multirow{2}{*}{0.817} \\
\hline & females & 92 & 181.152 & 14.529 & & \\
\hline
\end{tabular}

The results in Tables 4-6 indicated that there were statistically significant differences in spiritual mindfulness, spiritual abilities, spiritual presence, spiritual intelligence, and adherence to ethical standards of scientific research $(99.614,129,783,134,917$, $166,583)$ respectively. The differences were in the favor of professor researchers. These results have been tested for significance at the .05 level. The results in Tables 7-9 showed that spiritual intelligence is significantly predicted to adhere to ethical standards of scientific research. The correlation of 0.818 indicated that the model predicted $81.8 \%$ of the variation in adherence to research ethical standards.

Table 4: Means and standard deviations of domains scores of spirituality intelligence and adherence to ethical standards.

\begin{tabular}{|c|c|c|c|c|}
\hline Measure & Groups & $\mathbf{N}$ & $\mathbf{M}$ & SD \\
\hline \multirow{4}{*}{ Spiritual Mindfulness } & 1.00 & 106 & 14.8491 & 3.58779 \\
\hline & 2.00 & 43 & 19.6744 & 3.87741 \\
\hline & 3.00 & 54 & 24.4259 & 5.13443 \\
\hline & Total & 203 & 18.4187 & 5.77953 \\
\hline \multirow{4}{*}{ Spiritual Abilities } & 1.00 & 106 & 14.7170 & 3.71292 \\
\hline & 2.00 & 43 & 19.3953 & 4.07162 \\
\hline & 3.00 & 54 & 24.9815 & 3.88267 \\
\hline & Total & 203 & 18.4384 & 5.78577 \\
\hline \multirow{4}{*}{ Spiritual Presence } & 1.00 & 106 & 14.6792 & 3.56584 \\
\hline & 2.00 & 43 & 19.4186 & 4.39281 \\
\hline & 3.00 & 54 & 25.7037 & 4.56248 \\
\hline & Total & 203 & 18.6158 & 6.14673 \\
\hline \multirow{4}{*}{ Spiritual Presence } & 1.00 & 106 & 44.2453 & 9.51972 \\
\hline & 2.00 & 43 & 58.4884 & 10.29418 \\
\hline & 3.00 & 54 & 75.1111 & 11.31982 \\
\hline & Total & 203 & 55.4729 & 16.55124 \\
\hline \multirow{4}{*}{ Spiritual Presence } & 1.00 & 106 & 169.6321 & 6.66523 \\
\hline & 2.00 & 43 & 185.3023 & 3.70672 \\
\hline & 3.00 & 54 & 201.4630 & 6.78987 \\
\hline & Total & 203 & 181.4187 & 14.88494 \\
\hline
\end{tabular}


Table 5: One Way Anova test for statistical significance among spirituality intelligence and ethical adherence.

\begin{tabular}{|c|c|c|c|c|c|c|}
\hline \multicolumn{2}{|c|}{ Variables } & Sum of Squares & df & M & $\mathbf{F}$ & Sig. \\
\hline \multirow{3}{*}{$\begin{array}{c}\text { Spiritual } \\
\text { Mindfulness }\end{array}$} & Between Groups & 3367.178 & 2 & 1683.589 & 99.614 & 0.000 \\
\hline & Within Groups & 3380.230 & 200 & 16.901 & & \\
\hline & Total & 6747.409 & 202 & & & \\
\hline \multirow{3}{*}{ Spiritual Abilities } & Between Groups & 3819.210 & 2 & 1909.605 & 129.783 & 0.000 \\
\hline & Within Groups & 2942.770 & 200 & 14.714 & & \\
\hline & Total & 6761.980 & 202 & & & \\
\hline \multirow{3}{*}{ Spiritual Presence } & Between Groups & 4383.211 & 2 & 2191.605 & 134.917 & 0.000 \\
\hline & Within Groups & 3248.819 & 200 & 16.244 & & \\
\hline & Total & 7632.030 & 202 & & & \\
\hline \multirow{3}{*}{$\begin{array}{c}\text { Spiritual } \\
\text { Intelligence }\end{array}$} & Between Groups & 34578.901 & 2 & 17289.450 & 166.583 & 0.000 \\
\hline & Within Groups & 20757.700 & 200 & 103.789 & & \\
\hline & Total & 55336.601 & 202 & & & \\
\hline \multirow{3}{*}{ Adhere to Ethics } & Between Groups & 37070.262 & 2 & 18535.131 & 482.362 & 0.000 \\
\hline & Within Groups & 7685.147 & 200 & 38.426 & & \\
\hline & Total & 44755.409 & 202 & & & \\
\hline
\end{tabular}

Table 6: Multiple Comparison using Scheffe test among domains of spirituality intelligence and ethical adherence.

\begin{tabular}{|c|c|c|c|c|c|}
\hline Dependent Variable & (I) Scientific degree & (J) Scientific degree & Mean Difference (I-J) & Std. Error & Sig. \\
\hline \multirow{6}{*}{ Spiritual mindfulness } & \multirow{2}{*}{1.00} & 2.00 & $-4.82536-*$ & .74330 & 0.000 \\
\hline & & 3.00 & $-9.57687-*$ & .68733 & 0.000 \\
\hline & \multirow{2}{*}{2.00} & 1.00 & $4.82536^{*}$ & .74330 & 0.000 \\
\hline & & 3.00 & $-4.75151-*$ & .84026 & 0.000 \\
\hline & \multirow{2}{*}{3.00} & 1.00 & $9.57687^{*}$ & .68733 & 0.000 \\
\hline & & 2.00 & $4.75151^{*}$ & .84026 & 0.000 \\
\hline \multirow{6}{*}{ Spiritual abilities } & \multirow{2}{*}{1.00} & 2.00 & $-4.67837-*$ & .69354 & 0.000 \\
\hline & & 3.00 & $-10.26450-*$ & .64132 & 0.000 \\
\hline & \multirow{2}{*}{2.00} & 1.00 & $4.67837^{*}$ & .69354 & 0.000 \\
\hline & & 3.00 & $-5.58613-*$ & .78400 & 0.000 \\
\hline & \multirow{2}{*}{3.00} & 1.00 & $10.26450^{*}$ & .64132 & 0.000 \\
\hline & & 2.00 & $5.58613^{*}$ & .78400 & 0.000 \\
\hline \multirow{6}{*}{ Spiritual presence } & \multirow{2}{*}{1.00} & 2.00 & $-4.73936-*$ & .72871 & 0.000 \\
\hline & & 3.00 & $-11.02446-*$ & .67384 & 0.000 \\
\hline & \multirow{2}{*}{2.00} & 1.00 & 4.73936* & .72871 & 0.000 \\
\hline & & 3.00 & $-6.28510-*$ & .82376 & 0.000 \\
\hline & \multirow{2}{*}{3.00} & 1.00 & $11.02446^{*}$ & .67384 & 0.000 \\
\hline & & 2.00 & $6.28510^{*}$ & .82376 & 0.000 \\
\hline \multirow{6}{*}{ Spiritual intelligence } & \multirow{2}{*}{1.00} & 2.00 & -14.24309-* & 1.84196 & 0.000 \\
\hline & & 3.00 & $-30.86583-*$ & 1.70328 & 0.000 \\
\hline & \multirow{2}{*}{2.00} & 1.00 & $14.24309^{*}$ & 1.84196 & 0.000 \\
\hline & & 3.00 & $-16.62274-^{*}$ & 2.08223 & 0.000 \\
\hline & \multirow{2}{*}{3.00} & 1.00 & $30.86583^{*}$ & 1.70328 & 0.000 \\
\hline & & 2.00 & $16.62274^{*}$ & 2.08223 & 0.000 \\
\hline \multirow{6}{*}{ Adherence to Ethics } & \multirow{2}{*}{1.00} & 2.00 & $-15.67025-*$ & 1.12077 & 0.000 \\
\hline & & 3.00 & $-31.83089-*$ & 1.03639 & 0.000 \\
\hline & \multirow{2}{*}{2.00} & 1.00 & $15.67025^{*}$ & 1.12077 & 0.000 \\
\hline & & 3.00 & $-16.16064-*$ & 1.26697 & 0.000 \\
\hline & \multirow{2}{*}{3.00} & 1.00 & 31.83089* & 1.03639 & 0.000 \\
\hline & & 2.00 & $16.16064^{*}$ & 1.26697 & 0.000 \\
\hline
\end{tabular}


Table 7: Model summary.

\begin{tabular}{|c|c|c|c|c|}
\hline Model & R & R Square & Adjusted R Square & Std. Error of the Estimate \\
\hline 1 & $.814^{\mathrm{a}}$ & 0.662 & 0.66 & 8.67617 \\
\hline
\end{tabular}

a. Predictors: (Constant), spiritual intelligence.

Table 8: The results of Anova test for regression model.

\begin{tabular}{|c|c|c|c|c|c|c|}
\hline \multicolumn{2}{|c|}{ Model } & Sum of Squares & df & Mean Square & F & Sig. \\
\hline \multirow{3}{*}{1} & Regression & 29624.9 & 1 & 29624.9 & 393.551 & $0.000^{\mathrm{b}}$ \\
\cline { 2 - 7 } & Residual & 15130.5 & 201 & 75.276 & & \\
\cline { 2 - 7 } & Total & 44755.4 & 202 & & & \\
\hline
\end{tabular}

a.

Dependent Variable: adherence to ethical standards.

b. Predictors: (Constant), Spiritual Intelligence.

Table 9: Coefficient of study variables included in study model.

\begin{tabular}{|c|c|c|c|c|c|c|}
\hline & \multirow{2}{*}{ Model } & \multicolumn{2}{|c|}{ Unstandardized Coefficients } & \multirow{2}{*}{$\begin{array}{c}\text { Standardized Coefficients } \\
\text { Beta } \\
\end{array}$} & \multirow{2}{*}{$\mathbf{t}$} & \multirow{2}{*}{ Sig. } \\
\hline & & B & Std. Error & & & \\
\hline \multirow{2}{*}{1} & (Constant) & 140.83 & 2.135 & & 65.972 & 0 \\
\hline & Spiritual intelligence & 0.732 & 0.037 & 0.814 & 19.838 & 0 \\
\hline
\end{tabular}

a. Dependent Variable: adherence to ethical standards.

\section{Discussion}

The findings of this study indicated that there was a low level of spiritual intelligence among academic researchers, this indicates that the researchers have low scores of spiritual mindfulness, spiritual abilities, spiritual presence, and low level in the total scores of spiritual intelligences. These results may be due to the conflicts and stressors that academic researchers confront in their life in home and work, that lead to minimize their spiritual intelligence. The unresolved conflicts caused tension, anxiety, decreased quality of life. Because of the globalization of human qualities and the rapid changes in all aspects of life, as well the cultural and cognitive conflict, all these making the academic researcher's life a series of successive events, and stressed the principle of materialism and utilitarianism, and decreased their spiritual intelligence, which is like the oil that makes the gears of life spin and walk them easily towards their scientific aims, make their communicate with academic co-workers effectively, gain confidence, create a positive impression to them, and then feel happy in family and academic life.

As well, the results showed that the researchers have an average level of adherence to the research ethical standards of procedures, intellectual property rights, social responsibility, guidance, supervision, and arbitration of letters, scientific research and the rights of research colleagues. This confirms the need to draw the attention of officials and those concerned with scientific research at the university. This result is not consisted with the study of Arnout [16] which found a average level of researcher adherence to ethics. This result may be due to two reasons the first is the lack of awareness among researchers at the university of some ethical standards that must be adhered to it, as well as the importance of adhering to the ethics of scientific research and realizing that it is in the interest of research. And the second reason is the lack of evidence of the ethics of scientific research in universities to guide them in their various scientific behaviors, as well as the absence of the university ethics committee. The finding regarding the differences between males and females in spiritual intelligence and adhere to ethical standards. This result is consisted with the results of $[27,30,31]$, but not compatible with results of Al-Rapia [35] study. This result may be due to the methods of socialization prevailing in the Arab society, which emphasizes the necessity of female commitment to ethics and rules or else subjected to deterrent punishment, and therefore the researchers increased their concern not to fall into scientific transgressions. This may also be due to the female personality traits and ways of thinking of a tendency to maintain the standards of society and traditions and customs for fear of punishment if they violated or erred.

The result of the study also indicated that the professors have high scores of spiritual intelligences and adhere to ethical standards than assistance and associate professors. The result may be due to the increased experience of professors in the ethics of scientific research in citation, translation, and other research activities, as a result of their scientific experience. It may also be attributed to the increased awareness of the importance of adherence to the ethics of scientific research and necessity; this has increased the interest and awareness of professors and associate professors in risk and damage beyond the violation ethics of scientific research, which may expose them to legal accountability and defamation in the university community. In contrast to the associate professors who are still needed to develop and raise awareness of ethical standards. The regression analysis with spiritual intelligence and adhere to ethical standards results indicated that spiritual intelligence has a significant statistical contribute to adhere to ethical standards of scientific research $(\mathrm{R}=0.814)$. This result consisted with what the 
Costello [25] who argued, that Spiritual intelligence indicates the direction your body, heart, and mind must constantly take to get what you want from life. It is also the engine that leads you towards meaning, your need to connect with your Creator in the broad sense of the word and indicates your need to communicate with something far greater than yourself Individual. Covey [36] emphasized that spiritual intelligence is the central and important intelligence among other intelligences, because it includes the vital qualities of the individual such as energy, determination, enthusiasm, and the development of an individual's moral identity. Thus, spiritual intelligence is very important to academic researchers because it helps them for development of their moral and scientific identity, also increases their awareness and adherence to the ethics.

The researcher's commitment to ethical standards related to research procedures enables him to choose problems that touch the reality of the society and the suffering of its members and seeks the seriousness, uniqueness and excellence in the research subjects, and the use of new methods in studying and seeking solutions in creative ways, as well as human and animal rights as participants in the research. The researcher's respect for the intellectual property rights of others and their achievements and their preservation, whether in transport, citation, publishing, translation or other scientific activities, makes his research unique and transparent and fair, and does not seek to be merely a vector of others' efforts but creative and innovative. May be located by other researchers who do not adhere to ethics in scientific research, creativity includes the elements of originality and innovation at the same time. The researcher's sense of social responsibility during the design of the research and the procedures of its implementation makes it more careful to avoid damage to individuals or society and minimizing risks to the minimum. The uses innovative methods and methods, benefits from modern technology and uses the resources available to him in university and society wisely, realistic and useful solutions to problems. As well as the researcher's commitment to his responsibilities towards his research, knowledge of the responsibilities of his supervisor and his powers in supervising and the supervisor himself duties to the researcher to be supervised by an official contributes to the development of the researcher's capabilities and self-confidence and respects his views, the researcher can be innovative in his research through scientific supervision supportive scientific approaches, in accordance with clear and specific criteria that guarantee the integrity and transparency of scientific research without distinction as to race, sex or other reasons, increases the quality of the scientific research process and makes the university a prestigious place within the global classification in the field of scientific research.

Success in academic activities for researchers requires a variety of linguistic, logical, mathematical, spatial, physical, motor and musical intelligences in relation to others, and inner personal intelligence. Piaget pointed out that intelligence is an aspect of an individual's adaptation to his environment; adjustment involves the interaction between two mental processes of assimilation and harmony $[37,38]$. Spiritual intelligence opens the academic researchers heart, illuminates their mind, enables them to distinguish between reality and fantasy in their studies, to discover the hidden happy and joy under stress of daily life and work, to see problems and Phenomena as they are away from unconscious distortion, and can be expressed through any culture as love, wisdom and service humanity. Thus, spiritual intelligence predicts to adherence to search standards among researchers, because the concept of spiritual intelligence is related to human nature or what we call instinct. The nature of man is spirituality, religiosity and goodness, and therefore this nature must be preserved to organize human life.

Also, commitment to worship as a way of life, and adherence to ethics that will sharpen the personality of man and strengthen the relationship between the servant and his Lord, and also between him and others, and to increase the awareness of the person and the world and the whole universe, Which leads to a balance in the life of the individual in the light of the standards, and leads individuals to make internal and global peace and maintain their health and wellbeing, because spiritual intelligence that unites and directs the other intelligences of the individual. Spiritual intelligence determines the human behavior in every aspects of life in home and work, in family and with friends. Spiritual intelligence predicted adherence to search standards, because spiritual intelligence emerged as a result of integrating intelligence with spirituality. It is clearly that the spiritual intelligence contains a combination of abilities: analytical, creative, and practical. Analytical abilities are employed in critical existential thinking, in the production of academic researcher meaning, and in transcendental awareness. Creative abilities are used in varying levels in all spiritual intelligence capacities, while practical capacities include adaptive applications of all abilities, such as academic researcher's conscious awareness of ethics.

\section{Conclusion and Recommendations}

In summary, the present study examined the relative contribution of spiritual intelligence and adherence to ethical standards of scientific research. Future research should investigate the effectiveness of applied interventions designed to increase spiritual intelligence and adherence to ethical standards to bring about improved performance and quality of scientific researches. Because the researchers in different scientific degree must be keen to adhere to ethical standards in research procedures, intellectual property rights and social responsibility, to supervise master's and doctoral students, to arbitrate and to participate in scientific discussions, as well as to respect the rights of colleagues and researchers, whether in individual or collective research with other colleagues.

\section{References}

1. Ibrahim M (2000) Foundations of scientific research for the preparation of university letters. Al Warraq Publishing \& Distribution Est, Jordan. 
2. (2017) University of Cambridge, Research Integrity and Good Research Practice Checklist for Supervisors of Research Students.

3. (2016) University of South Africa, Policy on Research Ethics. UNISA.

4. Honderich $\mathrm{T}$ (2003) Consequentialism, moralities of concern and selfishness. Unpublished manuscript.

5. Steneck N (2007) Introduction to the responsible conduct of research.

6. Awad M (2005) Ethics of Scientific Research. Working paper presented at the Forum of the Accreditation Council, Ministry of Higher Education, Higher Education and Globalization - Towards a Charter of Ethical Action, Amman, Jordan.

7. Goulart B, Levey S, Rech R (2018) The role of ethics and research integrity in the training of health professionals and in the development of human research. Rev 20(5).

8. Chabon S, Morris JF (2004) A consensus model for making ethical decisions in a less-than-ideal world. The ASHA Leader 18-19.

9. Guraya S, London N, Guraya S (2014) Ethics in medical research. Journal of Microscopy and Ultrastructure 2(3): 121-126.

10. Briggs H (2017) Fake research comes under scrutiny. British Broadcasting Corporation.

11. Frigate G (2001) Culture of Scientific Research. Jordan: Dar Al Yazouri Scientific Publishing and Distribution.

12. Vasconcelos S, Sorenson M, Watanabe E, Foguel D, Palácios M (2015) Brazilian science and research integrity: where are we? What next? An Acad Bras Cienc 87(2): 1259-1269.

13. Khadr A (1992) The Crisis of Scientific Research in the Arab World. Riyadh: Salah Al-Hujailan Office.

14. Resnik D (2015) What is Ethics in Research \& Why is it Important?

15. Fawaz F (2018) Ethics of Scientific Research. Journal of Islamic Sciences 18: $551-592$

16. Arnout B (2019) Adhere to ethical standards of scientific research and its relation to creativity in psychological and educational research in the light of some demographic variables: exploratory study. The Arab Journal for Science and the Dissemination of Research, Journal of Educational and Psychological Sciences 2(3): 21-51.

17. Sohrabi F (2006) An introduction to spiritual intelligence. Manna Journal, Psychology of Religion 2.

18. Emmons R (2000) Is Spirituality Intelligence? Motivation, Cognition and the Psychology of Ultimate Concern, International Journal for the Psychology of Religion 10(3): 3-26.

19. Mayer J (2000) Spiritual intelligence or spiritual consciousness. The International Journal for The Psychology of Religion 10(1): 47-56.

20.Zohar D, Marshall I (2000) SQ-Spiritual intelligence. London: Bloomsbury Publishing.

ISSN: 2574-1241

DOI: 10.26717/BJSTR.2019.18.003216

Ahed J Alkhatib. Biomed J Sci \& Tech Res

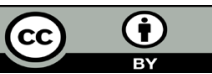

This work is licensed under Creative Commons Attribution 4.0 License

Submission Link: https://biomedres.us/submit-manuscript.php
21. Wolman R (2001) Thinking with your soul: Spiritual intelligence and why it matters. Harmony Books, New York, USA.

22. Amram Y, Alto P (2007) The seven dimension of spiritual intelligence: An ecumenical grounded theory. $115^{\text {th }}$ The Annual Conference Of The American Psychological Association: San Francisco 17-20.

23. King D (2008) Rethinking claims of spiritual intelligence: A definition, model, and measure. Unpublished Master Thesis, Trent University, Peterborough, Ontario, Canada.

24. Wigglesworth C (2004) Spiritual intelligence and why it matters.

25. Costello M (2013) How to increase your spiritual intelligence. Personal development

26. Vama Mar A (2011) What is spiritual intelligence.

27. Arnout B (2016) Development of the scale of spiritual intelligence of the disabled and the special needs of adolescents and adults. psychological guidance Journal, Ain Shams University 46: 155-198.

28. Vaughan F (2002) What is spiritual intelligence? Journal of Humanistic Psychology 42(2): 16-33.

29. Joseph J (2004) The fourth wave in business.

30. Arnout B (2007) Spiritual Intelligence and its Relationship to Personality Characteristics in Different Age Samples. Journal of the Faculty of Education, Banha University 17(72): 125-190.

31. Arnout B (2008) Spiritual Intelligence and its Relationship to Quality of Life. Journal of the Modern Education Association 313-389.

32. Amrai K, Farahani A, Ebrahimi M, Bagherian V (2011) Relationship between personality traits and spiritual intelligence among university students. Procedia Soc Behav Sci 15: 609-612.

33. Beshideh K, Charkhabi M, Kalkhoran M (2011) Relation between personality traits and spiritual intelligence in male students of Shahid Chamran University at Ahvaz, International Journal of Psychology 5(1): 21-34.

34. Abadi M, Farid A, Bahari F, Chami M (2012) The Effect of Islamic Fasting in Quran on Spiritual Intelligence and Happiness of Fasting Persons, Quran Med 1(3): 66-70.

35. Al Rapia F (2013) The spiritual intelligence and its relation to sex and the level of achievement among students of the Faculty of Education at Yarmouk University in Jordan. Jordanian Journal of Educational Sciences 9(4): 353-364.

36. Coffee S (2006) The eighth habit. Damascus, Dar al-Fikr.

37. Hamidreza Babaee Bormanak, Yasin Khoshhal (2017) The role of equilibration in Piaget's Theory of Cognitive Development and Its Implication for Receptive Skills: A theoretical study. Journal of Language Teaching and Research 8(5): 996-1005.

38. Rudowicz E (2003) Creativity and culture: A two way interactions. Scandinavian Journal of Educational Research, 47(3): 273- 290.

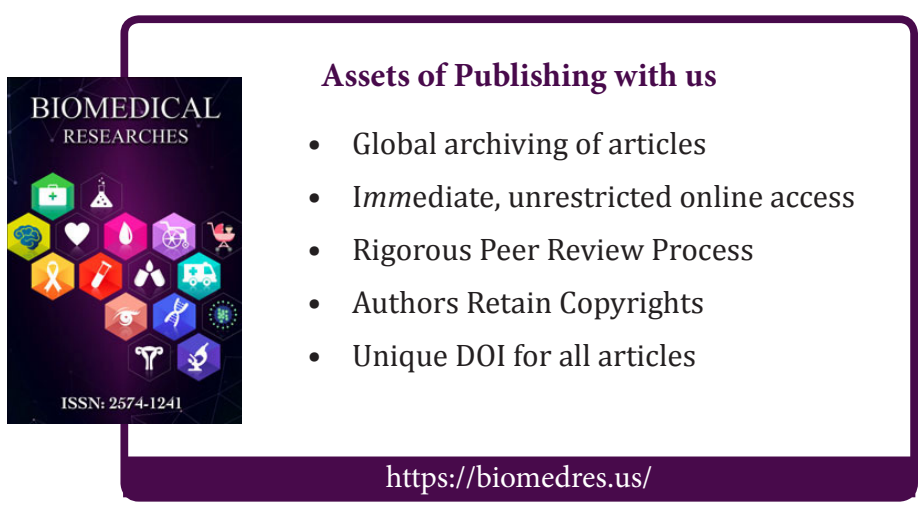

